Margaret Atwood finally links her own work to some of the imagery and Native lore she has been discussing, which gives a sort of circular structure to the book. What one misses here perhaps is a much more detailed analysis of her own writing, inextricably linked to the imagery of the Canadian North, a Canadian North which could cease to exist because of pollution and environmental carnage. She thus finishes her fourth lecture, and this book, by drawing the listener's, and the reader's, attention to environmental problems in Canada. Strange Things offers a fascinating portrait of the Canadian North, and an insight into the Canadian literary imagination. Both informative and exciting, it provides a very illuminating understanding of the mysterious North and of its lore, which has always allured poets and novelists alike. Atwood's Strange Things constitutes then a useful book to those who want to focus on the relationship between the Canadian North and story-telling, as well as a valuable piece of literature in itself.

Rosario Arias

Charles Bernheimer (ed.), Comparative Literature in the Age of Multiculturalism, Baltimore \& Londres, The John Hopkins University Press ("Parallax; Re-visions of Culture and Society"), 1995, 207 pp.

The volume that we are commenting is composed of three parts. If we do not take into account Bernheimer's preliminary chapter on "The Anxieties of Comparison", the first part gathers "Three Reports to the American Comparative Literature Association", elaborated by the commissions that presided professors Harry Levin in 1965, Thomas Greene in 1975 and Charles Bernheimer in 1993. These are the successive reports that have oriented their guidelines in the exercise of the comparative literature as an accademic discipline in American Universities. In the second part come together "Three Responses to the Bernheimer Report at the Modern Language Association Convention, 1993". The book is completed with a section of "Position Papers", in which appear thirteen articles prepared after the debate provoked by the Bernheimer Report, in 1993.

The paper entitled "Comparative Literature at the Turn of the Century" is the central one in this volume, for it contains many recommendations to renove the comparative research and to shape the new universitary Programs of Comparative Literature at Graduate and Undergraduate levels. Berheimer's Report, trying to sum up hte mos relevant contents of 1965 and 1975 previous Reports, draws a living picture of the major vicissitudes and mutations that comparative studies have experienced in the last thirty years. The editor of those Reports pointed out the growth of the discipline after World War II, based in the adoption of broader perspectives, but after all, it "did not often reach beyond Europe's high-cultural lineage going back to the civilizations of classical antiquity" (p. 40). That situation lead "to reinforce an identification of nation-states as imagined communities with national languages as their natural bases" (p. 40). In spite of warning about the dangers that threatened the comparativism of those days, inspired by traditional and immobilized conceptions, Levin and Green complained against the attempts of mining "the very basis of comparative literature's elite image" (p.40) of those who, by reasons of comfort, adopted translations instead of commenting the texts in their 
original languages. They also manifested some reserve towards multidisciplinarity, as it showed an inherent impunity in the diversification of approaches, and towards literary theory, that was in fashion during the seventies.

The authors of the 1993 Report figth for a radical redefinition of goals and methods, since, as they admit, "the dangers confronting the discipline thus constructed [in the traditional eurocentric way] have only intensified in the seventeen years since the publication of the Green report, to the point that, in the opinion of this commitee, the construction no longer corresponds to the practices that currently define the field" (p. 41).

In the nineties those practices have got in tune with the multicultural trends which have pervaded the speech of Humanities. In this case, the new bias intended for the subject is dangerously adjacent to the so-called "Cultural Studies", a field that has arisen many intellectual ravings. As it is already known, the criticism addressed to mulculturalism - and it should be remembered that the attacks have been formulated not only from retrograde ideological fields- maintains that it breathes the wish that all cultures be treated on equal terms, in an attempt, more o less unconfessed, of destruction and refill of imposed cultural prestiges -if we echo well known arguments- arrogantly enough through the political action of the western colonizer powers and because of the patriarcal preponderancies that should be eliminated now, given the failure of previous efforts, more conciliatory and moderate, to put them a stop. To tell the truth, Bernheimer's Report sanctions a given situation, that is sumed up in the following terms: "The space of comparison today involves comparisons between artistic productions usually studied by different disciplines; between various cultural constructions of those disciplines; between Western cultural traditions, both high and popular, and those of non-Western cultures; between the pre- and postcontact cultural productions of colonized peoples; between gender constructions defined as straight and those defined as gay; between racial and ethnic modes of signifying; between hermeneutic articulations of meaning and materialist analysis of its modes of production and circulation; and much more" (p. 42). This directly flows into one of the most controversial thesis of the Report - severely criticized by Rifaterre in the same volume, in one of the commentaries to the 1993 guidelines-: " These ways of contextualizing literature in the expanded fields of discourse, culture, ideology, race, and gender are so different from the old models of literary study according to authors, nations, periods, and genres that the term "literature" may no longer adequately describe our subject of study" (p. 42). Nevertheless, to that is added the reserve that "our recommendation to broaden the field of inquiry [...] does not mean that comparative study should abandon the close analysis of rhetorical, prosodic, and other formal features but textually precise readings shooooould take account as well of the ideological, cultural, and institutional contexts in which their meanings are produced" (p. 43). With regard to language knowledge, it is recommended to the students of the speciality "to broaden their linguistic horizons to encompass at least one non-European language" (p. 43), though "the old hostilities toward translation should be mitigated" (p. 44), since firstly "translation can well be seen as a paradigm for larger problems of understanding and interpretation across different discursive traditions" (p. 44) y also because "it may be better, for instance, to reach a work in translation, even if you don't have acess to the original language, than to 
neglect marginal voices because of their mediated transmission" (p. 44). The canon's formation and reshaping is to be, of course, another

central issue of the new comparativism: "comparative literature courses should teach not just "great books" but also how a book comes to be designated as "great" in a particular culture, that is, what interests have been and are invested in maintaining this label" (p. 46). Summing up the authors' goals, it is affirmed: "Our report puts forward some guiding ideas about the way curricula can be structured in order to expand students' perspectives and stimulate them to think in culturally pluralistic terms" (p. 47).

As we have already said, the volume includes three answers to the 1993 Report. Dissenting in many points is Michel Rifaterre's essay, "On the Complementarity of Comparative Literature and Cultural Studies". More consently are those of Anthony Appiah ("Geist Stories") and Mary Louise Pratt ("Comparative Literature and Global Citizenship"). The authors of the papers that complete the work are researches of american universities: Ed Ahearn and Arnold Weinstein ("The Function of Criticism at the Present Time: The Promise of Comparative Literature"), Emily Apter ("Comparative Exile: Competing Margins in the History of Comparative", Peter Brooks ("Must We Apologize?"), Rey Chow ("In the Name of Comparative Literature"), Jonathan Culler ("Comparative Literature, at Last!"), David Damrosch ("Literary Study in an Elliptical Age"), Elisabeth Fox-Genovese ("Between Elitism and Popularism: Whither Comparative Literature?"), Roland Greene ("Their Generation"), Margaret R. Higonnet ("Comparative Literature on the Feminist Edge"), Françoise Lionnet ("Spaces of Comparison"), Marjorie Perloff ("'Literature' in the Expanded Field"), Mary Russo ("Telling Tales out of School: Comparative Literature and Disciplinary Recession"), Tobin Siebers ("Sincerely Yours").

Santiago Navarro Pastor - Heinrich Heine-Universität Düsseldorf.

\section{Esther Morillas y Juan Pablo Arias, eds. El papel del traductor. Salamanca: Ediciones Colegio de España, Biblioteca de Traducción, 1997, 509 pp.}

It is no exaggeration to say that translation has become one of the foundations on which our modern life is built. Indeed, the importance of translation is now more and more widely acknowledged. This is certainly the case in the academic domain, since, for the last two decades, experts in the field have been wholeheartedly proclaiming the autonomy of Translation Studies as an independent discipline. But even the layman will concede that, in the era of supranational political decision-making, cross-border regulation, thriving international trade and global cyberculture, one cannot do without translation.

However, this widespread belief contrasts with the paradoxical underestimation of the translator's status and responsibilities. In the social arena, the translator's task receives low regard, probably due to the general unawareness of the specific skills and the high degree of specialization required. As for theory, many questions concerning how the personal stance of the translator influences the final product still remain unanswered. From a historical point of view, the importance of translators in the shaping of particular cultures 